DOI: $10.30973 /$ esdi/2018.4.2/5

ISSN: $2448-4857$

Volumen 4 | Número 2

septiembre 2018 |febrero 2019

pp. 78-93

\title{
El arte, la mesa de existencia y los anhelos de mundo: discursos y silencios en la era de la globalización
}

\author{
Art, the Table of Life, and World Aspirations: Discourse \\ and Silence in the Era of Globalisation
}

\author{
María Antonia Hidalgo Rubio \\ Universidad Pablo de Olavide \\ mahid@upo.es
}

\begin{abstract}
Resumen
El presente ensayo invita a una reflexión sobre los procesos de la imaginación creadora y el sentir social hacia la construcción de mundos posibles a través de determinados discursos que generamos y, por tanto, de la legitimidad que les otorgamos. También trata sobre aquellas personas que tienen derecho a hablar y las que no, discursos no nacidos o silenciados en los que el arte se constituye como agente de voz y memoria. La "mesa de existencia” hace referencia según Bachelard a un espacio físico y simbólico para habitar, organizar nuestras experiencias y narrar lo vivido.
\end{abstract}

Palabras clave: arte, sociedad, memoria, globalización, filosofía

\begin{abstract}
The present dissertation invites us to reflect upon the processes of creative imagination and social conscience towards the construction of potential worlds through specific discourses we generate and therefore legitimize. This essay is also about those who possess the right to speak and those who don't, unborn or silenced discourses in which art represents both voice and memory. According to Bachelard, the Table of Life refers to a physical, as well as symbolic space in which we inhabit, organize, and narrate our life experiences.
\end{abstract}

Keywords: art, society, memory, globalization, philosophy

Fecha de recepción: 19 de junio de 2018 | Fecha de aceptación: 7 de septiembre de 2018 
El arte, la mesa de existencia y los anhelos de mundo

\section{El Sur Global y los procesos de creación}

La epistemología del Sur apunta fundamentalmente a prácticas de conocimiento que permitan intensificar la voluntad

de transformación social.

BOAVENTURA DE SOUSA SANTOS

$\mathrm{E}^{\mathrm{n}}$ n 1995, Santos, catedrático de Sociología de la Universidad de Coimbra, entendía por una epistemología del Sur ${ }^{1}$ la búsqueda de conocimientos y criterios de validez del conocimiento que otorgasen visibilidad y credibilidad a las prácticas cognitivas de los pueblos y los grupos sociales que han sido históricamente victimizados, explotados y oprimidos por el colonialismo y el liberalismo. Era necesaria la identificación de relaciones desiguales de poder-saber que subyacen a las epistemologías del Norte, entendido no ya geográficamente sino económica y geopolíticamente.

Para esa identificación, se hacía imprescindible contemplar los procesos económicos, sociales y políticos ocultos a la realidad visible, también en lo concerciente a la cultura y al arte. Contra la reducción de la realidad "a lo que se ve o existe" y las omisiones culturalistas que la sustentan, Santos presenta como propuesta central dos reflexiones: una sociología de las ausencias y una sociología de las emergencias, es decir, atender la parte de la historia del mundo que no se ha contado y hacerlo prioritariamente. Para ello formula con gran lucidez las tres orientaciones en que habría de basarse una epistemología del Sur: aprender que existe el Sur, aprender a ir al Sur, aprender a partir del Sur y con el Sur.

Es un Sur que también encontramos en el Norte global geográfico, representado en el sector que sufre las consecuencias de los mecanismos del poder,

\footnotetext{
${ }^{1}$ En un sentido literal y metafórico, el Sur se toma para hacer referencia a la población excluída y su sufrimiento. Santos es también el impulsor de la Universidad Popular de los Movimientos Sociales, cuya edición 2017 se celebró en los Campamentos de Refugiados Saharauis de Tinduf, concretamente en la Wilaya Bojador.
} 
María Antonia Hidalgo Rubio

marginación y exclusión, el llamado por este autor el Tercer Mundo Interior de los países hegemónicos (Santos 12).

Una reivindicación que aparecía en otros lenguajes artísticos como el poemario de Mario Benedetti El Sur también existe, cantado por Joan Manuel Serrat. De alguna manera, ya en los noventa, se hacía una llamada de atención que luego irrumpiría en el campo académico a través de una serie de experiencias emancipatorias con identidad propia.

Desde este punto, tal vez una de las razones que nos impulsan a plantear este ensayo sea la necesidad de recuperar el arte para no seguir perdiendo cuota de humanidad. Como diría Walter Benjamin, ${ }^{2}$ el ser humano siempre ha necesitado cobijo (54), pero nos convertimos en pobres, fuimos perdiendo un trozo de humanidad tras otro, depositándolos en la casa de empeño por un centésimo de su valor, para acabar recibiendo a cambio monedas sin valor de "actualidad".

Y ahora, en un tiempo de transición, en el que lo establecido y lo emergente conviven, se contradicen y compiten, se nos presenta también la oportunidad de "re-actualizarnos" y tomar decisiones conducentes a la construcción de un mundo con más sentido y menos asimetrías de poder, donde se promuevan acciones de equidad y justicia social, por pequeñas que estas sean, dentro y fuera de las universidades.

Ir hacia el Sur, aprendiendo desde el Sur no imperial, significa también ir más allá de la cartografía convencional académica del conocimiento. La cimentación de diálogos entre distintas luchas y saberes permiten dar visibilidad a personas y grupos sociales cuyas prácticas construyen (y se reconstruyen) a partir de tal conocimiento originario que les identifica y les interpela como pueblos.

Desde las ciencias sociales en general parece que, a paso lento, se va atendiendo este hecho, en particular desde la antropología, la sociología y la psicología social. Son ya muchos los ensayos e investigaciones de autores y autoras procedentes del Sur geográfico - África, América Latina y Asia-, que están vital e intelectualmen$\mathrm{t}$

${ }^{2}$ La obra de arte en la época de su reproducción mecánica, una de las últimas obras de Benjamin, que introduce conceptos dentro de la teoría del arte desde donde combatir los propósitos del fascismo (54). 
del lado del Sur metafórico, cerca de los oprimidos y explotados por las diferentes formas de dominación capitalista en su relación colonial con el mundo.

En cuanto a las prácticas culturales, uno de los objetivos de las epistemologías del Sur es visibilizar los modos de producción y representación de estos sectores desfavorecidos, culturas que sufren un epistemicidio, término acuñado por Santos para nombrar la destrucción violenta de los conocimientos, espiritualidades, formas artísticas, modelos igualitarios de organización social y de ejercicio del poder no occidentales considerados rudimentarios o anticuados.

La modernidad dicotómica ${ }^{3}$ (púbico/privado, conocimiento/afectos, Estado/ mercado), ha llevado a una homogeneización del mundo con la consiguiente eliminación de las diferencias culturales y artísticas, y el desperdicio de muchos conocimientos y experiencias enriquecedoras, sabias y fascinantes. Lo expresa también Eduardo Galeano: la cultura dominante admite a los indígenas y a los negros como objeto de estudio, pero no los reconoce como sujetos de la historia; tienen folclore, no cultura; practican supersticiones, no religiones; hablan dialectos, no idiomas; hacen artesanías, no arte (Tamayo 2008).

Es necesario geografiar ${ }^{4}$ la humanidad, la naturaleza, la ciencia, la cultura, el pensamiento de otra manera, más plural y contrahegemónica, más allá de la reducida cartografía eurocéntrica de la modernidad. Este es el principal desafío que tiene por delante el nuevo paradigma, donde las prácticas artísticas como procesos que favorecen la emancipación y la inclusión social han venido para quedarse, presentándose como una vía de hacerle frente a las diversas formas de exclusión y marginación que afectan a las comunidades del Sur Global.

\footnotetext{
${ }^{3}$ Una de las características de la modernidad era que se trataba de un proyecto (Albrow 1996) y su agencia fundamental era el Estado. Sin embargo, hoy, una de las lógicas definidoras de la tecnología de la información es la lógica de la interconexión (Castells 88), que lleva a consecuencias difícilmente previsibles, pero en las que suelen prevalecer los valores del mercado. La morfología de red, a la que lleva la lógica de la interconexión, permite la conexión entre individuos y agentes de cualquier tipo obviando los límites y fronteras claramente establecidos por la lógica territorializada del Estado. En la modernidad el Estado cerraba territorialmente las lógicas sociales, ahora no. Las dicotomías modernas inciden sobre lo público/privado, el conocimiento/los afectos, y el Estado/mercado, entre otras.

${ }^{4}$ Entiéndase aquí el término geografiar como la acción humana que haga un contrapeso los intereses la geopolítica actual.
} 
María Antonia Hidalgo Rubio

\section{El arte como voz y memoria: aproximaciones metodológicas}

Así como se hace necesario mapear e identificar un Sur Global y las consecuencias que el liberalismo económico y el colonialismo ejercen sobre él, para poder actuar sobre algunas evidencias, no ocurre lo mismo cuando hablamos de globalización, un concepto mucho más complejo de lo que salta a la vista. Lo que para unos es globalización, es localización para otros (Bauman 2001), procesos en los que se toma la parte por el todo, según vayan las finanzas, el comercio y el flujo de la información.

No olvidemos que la información y la comunicación son uno de los aspectos más destacables de la sociedad globalizada. El mundo de hoy es el resultado de un sistema capitalista neoliberal caracterizado por grandes cambios tecnológicos, el desarrollo de la informática y la expansión del mundo de las comunicaciones.

Otro aspecto de gran trascendencia es el marcado poder centralizador de las empresas transnacionales y del sistema financiero que marca y guía las políticas mundiales. Las enormes transformaciones en las que nos vemos inmersos también afectan a los sectores culturales (Musitu y Amador).

Las metodologías de aproximación desde lo cultural a las diversas problemáticas actuales, así como los canales de difusión que emplean cada una de las diferentes manifestaciones, no son los mismos, y, de este modo, tampoco la repercusión, el impacto y los resultados que se obtienen en los circuitos artísticos y sociales.

En este sentido, algunos autores se han aventurado a categorizar diferentes prácticas artísticas en base a sus tácticas de inserción en el contexto. Suzanne Lacy, ya en 1995 en Debated Territory: Toward a Critical Language for Public Art, establece cuatro modelos metodológicos de artistas, desde la esfera privada hacia la pública:

1. Artistas como experimentadores: aquellos que reflejan en un objeto físico-visual su experiencia subjetiva de la realidad. Lacy defiende que la percepción personal del artista experimentador, puede hacer cuestionar la realidad al resto de personas que cohabitan en ella. 
El arte, la mesa de existencia y los anhelos de mundo

2. Artistas como informadores: recuperan toda la información que supone su experiencia personal con la realidad, la filtra y la presenta al espectador después de hacer una selección consciente.

3. Artistas como analistas: colaboran con agentes especializados en otras disciplinas, normalmente del área social, con los que la realidad se somete a análisis, de manera que los resultados suelen presentarse como un artículo o texto para su difusión.

4. Artistas como activistas o artivistas: se organizan espontáneamente para crear y ejecutar acciones de activismo social o político a través de manifestaciones creativas muy diversas (performance, teatro, movimiento, artes plásticas) y consiguen involucrar al público y a la sociedad civil activamente. Las experiencias se tornan colectivas y la/el artista se convierte en el catalizador y promotor de ciertos cambios sociales.

En cualquiera de estas voces emergen las mismas interrogantes. Las respuestas, que originan a su vez nuevas interpelaciones, nos llevan a cuestiones de naturaleza casi siempre ontológica, que hacen que nos detengamos y capturemos la verdadera experiencia del contexto y sus imbricaciones socio-políticas, una experiencia sentida desde lo común y que tiene la responsabilidad de no contribuir a legitimar las desigualdades existentes.

Esta visión de un espacio reconocido como común supone una extensión creativa más sencilla y de alcance más humano, como diría Theodor Adorno; en la mirada de largo alcance, el impulso hacia el objeto queda detenido y sujeto a la reflexión, a una mirada que tiene lugar para salvaguardar la singularidad de las culturas, respetando su autonomía y sin perder, a su vez, la proximidad con éstas. Diríamos que su fórmula sería la proximidad con la distancia. ${ }^{5}$ Una proximidad suficiente para sumergirnos en el conocimiento de las variables socio-políticas que hayan propiciado la marginación de los territorios, sus saberes y sus gentes.

${ }^{5}$ Adorno aquí está cerca de Heidegger cuando habla de la necesidad de practicar la mirada contemplativa (Han 114). 
Esta proximidad nos ayuda a identificar las verdades tergiversadas, como las llama Guy Debord ${ }^{6}$ en La sociedad del espectáculo; la auto-emancipación de nuestra época consiste en desvincularnos de las bases materiales de la verdad tergiversada, pero el espectáculo vela el mal sueño de la sociedad moderna encadenada, que no expresa en última instancia más que su deseo de dormir.

Hoy se evita que miremos hacia los límites, se anula también lo diferente y extraño, lo que no es igual al resto. Pero no se enfrenta a ello; en palabras del filósofo coreano Byung-Chul Han, se trata más bien de una actitud de indiferencia, de dejar fuera lo ajeno a través de un tipo de violencia sutil y onmipresente.

Ahora, el Otro no puede integrarse de ninguna manera, pues el exceso de positividad, ${ }^{7}$ la sobreabundancia de lo idéntico, lo aniquila. La sociedad positiva, globalizada en su estructura neoliberal, no tiene ningún tipo de profundidad hermenéutica, no tiene tiempo para la poesía y evita toda crítica, toda modalidad de juego de la negatividad de lo extraño, que pudiera poner en riesgo su control. La positividad estabiliza y acelera el sistema por el hecho de que elimina lo diferente, no admite ningún sentimiento negativo, rechaza enfrentarse al sufrimiento y al dolor, a darles forma. Esta coacción sistémica convierte a la sociedad actual en una sociedad uniformada, según B. C. Han, en un infierno de lo igual.

Hay un problema, identificado ya por Walter Benjamin, visible también en el pensamiento de Guy Debord, Bauman, B. C. Han, Marina Garcés y Mónica Cavallé, entre otros, cuando alegan que la humanidad se ha convertido en espectáculo de sí misma y que su autoalienación ha alcanzado un grado que le permite vivir su propia destrucción como goce estético.

Por duro que parezca, lo vemos a diario en los medios de comunicación, que se han convertido en auténticos instrumentos de alienación y control geopolítico, desviando la atención de los problemas realmente importantes - o de sus causas de fondo- a través del bombardeo continuo de distracciones sin ningún tipo de

${ }^{6}$ La sociedad del espectáculo, uno de los retratos más agudos de la sociedad contemporánea, constituye la obra fundamental de Guy Debord (1931-1994), quien a su vez ha sido el principal agente de un movimiento de agitación cultural en Europa conocido como situacionismo, que planteó algunas de las propuestas más radicales, tanto en el terreno de la política como en el de la cultura después de la Segunda Guerra Mundial.

${ }^{7}$ Entendida como una sociedad plana, alienada, hiperinformada, sin criterio propio. 
El arte, la mesa de existencia y los anhelos de mundo

contenido cultural y educativo, como foros de cotilleos que promueven la idiotez y el ensañamiento, películas con alta carga violenta, certámenes gastronómicos estresantes y competitivos hasta el agotamiento, series para jóvenes que promueven lo fabuloso de tener músculos, aunque seas torpe e inculto; en definitiva, casi todo el menú televisivo gira en torno a cosas estúpidas e intrascendentes sin ningún mensaje constructivo, por no hablar de los telediarios, sus noticias de verdades tergiversadas, los discursos de resistencia silenciados y los genocidios consentidos, como es el caso palestino o saharaui, luchas que conozco más de cerca. ${ }^{8}$

Incluso las plataformas digitales - desde Facebook hasta Amazon - parece que generan un efecto de desintermediación, son sus algoritmos los que modelan el consumo y las interacciones de los usuarios, con el continuo bombardeo de productos publicitarios a tu medida, incluidos los artefactos culturales.

El mismo teléfono móvil es un aparato digital que trabaja con un input-output pobre en complejidad, fomenta la visión a corto plazo y ofusca la larga duración y lo lento. Con ello, se va olvidando pensar de una manera compleja, se atrofian formas de conducta que exigen una amplitud temporal o una amplitud de mirada, esa mirada de largo alcance a la que antes nos referíamos cuando hablábamos de los procesos creativos y mencionábamos a Adorno.

Nada del modus vivendi actual nos invita a detenernos y reflexionar sobre las consecuencias de la globalización en nuestras vidas. Desde una aproximación psicosocial, el primer concepto que se propone para entender la pobreza es el de marginación, término que se origina en la década de los cincuenta en el marco de la perspectiva desarrollista, principal ideología de la modernidad. Desde esta perspectiva, el marginado es representado como alguien ubicado en la periferia del desarrollo por encontrarse en una situación de disfunción o retraso social (Gallardo).

La degradación subjetiva atribuida al marginado, obtenida en trabajos etnográficos, dio origen al concepto de cultura de la pobreza. Desde este concepto, se admite una posición funcional que asume a los pobres como gestores de su propia situación de miseria. La pobreza se muestra como desastrosa e inevitable, pero

\footnotetext{
${ }^{8}$ Quisiera mencionar que mi investigación doctoral en la Universidad Pablo de Olavide de Sevilla, gira en torno a la memoria cultural de las mujeres saharauis refugiadas a través de sus dibujos.
} 
también se expone como una particular forma de existencia, como resultado de esa cultura de los pobres.

El análisis anterior entroncaría con las palabras de James C. Scott, en su libro Los dominados y el arte de la resistencia: "Un individuo que es ofendido puede elaborar una fantasía personal de venganza y enfrentamiento, pero cuando el insulto no es sino una variante de las ofensas que sufre sistemáticamente una raza, una clase o una capa social, entonces la fantasía se puede convertir en un producto cultural colectivo" (33).

Esto que postula Scott reconoce explícitamente que la geopolítica y sus formas de exclusión llevan aparejada una forma de geocultura pero, que a la vez, es también desde la organización cultural de las personas marginadas o socialmente excluídas desde donde se pueden dar respuestas. Lo vemos, por ejemplo, en las voces del rap palestino de la resistencia, el grupo DAM, o las raperas mexicanas Mare Advertencia LíriKa contra los feminicidios, el movimiento Bordamos por la Paz, el ya legendario Tucumán Arde de Rosario, Argentina, o ARTifariti, los Encuentros de Arte y Derechos Humanos en el Sáhara Occidental ${ }^{9}$ y en los Campamentos de Refugiados Saharauis de Tinduf, en el desierto argelino, proyecto en el que participo desde hace diez años junto a otros/as artistas, con la intención de acompañar y hacer visible una causa, marginada y olvidada por los medios de comunicación y la Comunidad Internacional.

9 La historia del conflicto del Sáhara Occidental se remonta al "reparto colonial africano" gestado en la Conferencia de Berlín de 1885. Después de 90 años de presencia española y promesas infinitas, España abandona el territorio en 1975, sin hacer cumplir la Resolución 1514 de las Naciones Unidas. Desde entonces, el Sahara Occidental fue engullido por Marruecos y la población saharaui se encuentra dividida entre las zonas ocupadas y el exilio en el desierto argelino en las proximidades de Tinduf. En el listado de Territorios No Autónomos (TNA) y la web oficial de Naciones Unidas aparece esta cita referida a la administración del Sáhara Occidental: "El 26 de febrero de 1976, España comunicó al Secretario General que a partir de dicha fecha daba por terminada su presencia en el territorio del Sáhara. En 1990 la Asamblea General reafirmó que la cuestión del Sáhara Occidental era un problema de descolonización que debía ser resuelto por el pueblo del Sáhara Occidental”. 
El arte, la mesa de existencia y los anhelos de mundo

Una movida hacia la reflexión y un espacio común: la mesa para sentir, crear y narrar

Desde estas luchas sociales, para comprender el mundo tantas veces se precisa sacar las cosas fuera de él, observarlas en un plano simbólico, establecer metáforas entre ellas y atender otras formas de comunicar, sentir y narrar.

Ética y estéticamente, en Cartas a Theo, Van Gogh hablaba de la necesidad de ser perseverantes en nuestras aspiraciones sobre el discurso de creación y no dejar nunca que se consuma el fuego del alma, sino, por el contrario, mantenerlo, para poder "hacer algo" allá donde hubiera todavía alma (85).

Quienes insistimos en buscar, al no renunciar a las tendencias centrífugas de la poética artística, algo nos conduce siempre a las imágenes y a sus periferias. En mi caso, al hablar de giro cultural, resulta inevitable pensar la movida española de los años ochenta y una de las canciones más recordadas que llevaba por título Malos tiempos para la lírica. ${ }^{10} \mathrm{~A}$ la vez que las ondas de algunas emisoras como Radio 3, Onda 2, Radio Popular, Radio Juventud y un puñado de locutores se empeñaban en demostraban que sí, que los tiempos estaban cambiando, otras personas hacían todo lo posible por mantener el status quo del franquismo. Pero en los ochenta los tiempos cambiaron, quien sabe si ahora la lírica tendrá los suyos.

Precisamente es desde un nuevo viraje cultural que se proponen otras maneras de pensar el arte, desestimando las raíces de la creación artística como dominación hegemónica a lo largo de la historia, alejándonos de esa concepción elitista y patriarcal, y abriéndonos a nuevos planteamientos que acercan el arte a su verdadera naturaleza democrática, la de facilitar la comunicación entre humanos, vinculándonos al análisis y a la acción social desde el Sur Global, a su devenir, e invitarnos a la reflexión, a mirar más adelante, o más atrás, o más adentro.

Para ese giro emancipador, sea cual sea la voz que desde las prácticas artísticas queremos alzar, se propone un encuentro alrededor de un elemento simbólico, la mesa, no una mesa cualquiera, sino la mesa de existencia.

${ }^{10}$ Tema del grupo gallego Golpes Bajos, uno de los representantes de la movida de Vigo en los ochenta. 
$\mathrm{Al}$ igual que la raza humana tiene un arma verdaderamente eficaz, la risa (palabras de Mark Twain con las que Joaquín Herrera Flores ${ }^{11}$ abre la introducción a O nome do riso. Breve tratado sobre Arte e Dignidade), tiene también la posibilidad de disponer de una mesa de existencia, un concepto que en Bachelard cumple la función de espacio de creación y reflexión, un lugar indispensable para la subjetividad que se nos describe como vital y necesario. Es, en cierta medida, una mesa para congregar y reseñar, un encuentro con la expresión singular de anhelos de mundo, de reconocimiento de una profunda existencia creativa común, un lugar desde donde crecer:

Una vez hecho el balance de las experiencias de la vida, experiencias mutiladas, mutilantes, es sobre todo ante mi papel blanco, ante la página blanca colocada sobre mi mesa a distancia justa de mi lámpara, donde realmente estoy ante mi mesa de existencia. Sí, es ante mi mesa de existencia donde he conocido la máxima existencia, le existencia en tensión, en tensión hacia delante, hacia más adelante, hacia lo alto. Todo alrededor es reposo, es tranquilidad, solo mi ser, mi ser en busca del ser se proyecta en la inverosímil necesidad de ser otro ser, un ser mayor. (Bachelard 94)

La cualidad de lo simbólico, esta capacidad de alimentar lo universal en la particular reflexión de Bachelard, solitario ante su mesa, nos orienta en relación a qué tipo de juego es el arte. El juego artístico, a diferencia de otros juegos que puedan existir, siempre busca la permanencia, cierta superación del tiempo. De alguna manera, lo simbólico del arte facilita el reconocimiento del origen, para emprender aquel Einhausung ("ir humano a casa") algo que nos pone delante de nuestra propia historia, como diría Gadamer (45)

Siguiendo este juego simbólico, en una habitación que bien pudiera ser la propia de Virginia Wolf o la buhardilla enjuta de Flaubert, poetas, artistas, arteterapeutas, docentes, investigadores e investigadoras, artivistas, gestores/as culturales, en la voluntad de contar y contarse, escapan al mundo para ver las cosas y luego

${ }^{11}$ Filósofo andaluz de los derechos humanos, profesor de la Universidad Pablo de Olavide y teórico de la cultura contemporánea, fallecido en 2009. 
El arte, la mesa de existencia y los anhelos de mundo

regresan "humanamente a casa" para conversar alrededor de la mesa, una y otra vez, unidos para captar la permanencia que les da el arte en lo fugitivo de la vida.

Ese ver las cosas guardaría relación con transitar por límites y periferias, ${ }^{12}$ espacios donde los criterios propios se mezclan y se hibridan con los de cualquier otro, sea quien fuere, en un encuentro de almas afines que constituyen, en cierta medida, el sí mismo encarnado en plenitud permitiéndose crear otros caminos, otras formas de ser, de sentir, de actuar.

Este arte potencialmente compartido, permitiría explorar y abrir otras posibilidades, otras realidades, nuevos mundos. Herrera Flores pone como ejemplo su viaje el ágora clásica, en la que los cínicos no filosofaban en el centro de la polis, sino que iban a las afueras de la ciudad a propiciar nuevos contactos y a reconstruir sus propias estatuas, sus propios criterios, de alguna manera, sus burlas del orden establecido y en definitiva, forjar sus propias identidades. En esa tarea, nos legaron una filosofía alegre y subversiva de los órdenes dominantes encapsulados y de las costumbres centrales asumidas como dogmas inamovibles por los que compartín el poder en la polis griega. En definitiva, lo que se propone y cada vez con más urgencia, es un cambio de paradigma desde las prácticas artísticas que asistan jubilosas al estímulo de la vida, no a su obstrucción.

Pero, ¿cómo sería el encuentro entre creadores y creadoras pensantes?, ¿qué forma tendría la mesa de existencia? La imagino redonda, sin aristas, en un alumbramiento nuclear y expansivo representando la esfera planetaria. En La llama de una vela Bachelard se refiere a un estado de ensueño primordial cuando vemos en nuestros propios sueños, o en la comunicación de los sueños ajenos, las raíces de la simplicidad. Frente una llama, dice, nos comunicamos moralmente con el mundo.

En los tiempos en los que se imaginaba pensando, sostiene el filósofo, la llama de una vela era una especie de manómetro sensible de la serenidad del alma, una medida de calma, la calma que desde la mesa de existencia desciende hacia los detalles cotidianos, y que en su duración sigue el curso de un ensueño tranquilo.

Reconfortan las palabras de Plutarco cuando se refiere a la mente humana no como una vasija que ha de ser llenada, sino como una luz que ha de ser encendida; y es un propósito vital el afán de iluminarnos, todavía, ante tantos mundos por

${ }^{12}$ En palabras de Herrera Flores, donde cada percepción del mundo pueda encontrarse. 
explorar, ante el fulgor de tantas luchas que acompañar, unidos y libres para encontrar nuevas respuestas y éstas, en sus luces, generar otros interrogantes para ser atendidos; así, en un diálogo valdelomariano ${ }^{13} \sin$ fin, sin ningún propósito de dominación, sino de emancipación y co-creación.

Podría ser que Val del Omar, como experto en periferias, se sumara al calor de nuestra mesa. Figura única de la historia del audiovisual y de las vanguardias españolas, José Val del Omar murió en el olvido rodeado de sus inventos, sus cámaras, sus máquinas, sus collages y sus latas llenas del cine más poético, audaz, alucinante y misterioso de lo que pueda imaginarse. Su laboratorio de creación, el PLAT (Tientos en Picto Lumínica Audio Táctil) era también un lugar existencial que tuve la oportunidad de visitar en su propia casa de Madrid, allá por 2006, años antes de que formara parte de la colección particular del Museo de Arte Reina Sofía.

Desde esas voces, posibilitemos encuentros para que se convoquen voluntades de creación y empatía, pensemos valientemente. El arte tiene un gran componente transformador, es visión y misión en su capacidad, protege de la alienación y atiende con esmero las heridas ontológicas. Sin procesos de creación, por otra parte, no habría experiencia estética, ni mesas de existencia, ni pensamiento valiente para la construcción conjunta de anhelos de mundo. ¡Desplacémonos!

La filósofa española Marina Garcés (Fuera de clase 38) define el pensamiento valiente como aquel que nos desplaza: lo que somos, lo que pensamos y lo que sabemos, dejan de mirarse al espejo para tenerse que mirar a través de los ojos, de las palabras, de las vidas, de las problemáticas de los otros, un pensamiento cuya mayor valentía es dejarse tocar. ¡Dejémonos tocar!

Hoy necesitamos una nueva movida transcultural, un nuevo lenguaje, una unión de lo lógico-conceptual con lo estético-intuitivo, donde resuenen nuestras alegorías y palabras sentidas, intuidas, tal vez no escritas, pero que a través de un sentir común se identifican y se entienden. Una movida como promesa de integración también para nosotros mismos, ávidos de conceptos y de anhelos de

${ }^{13}$ José Val del Omar (Granada, 1904-Madrid, 1982), inventor, cineasta, artista, poeta, visionario y místico. 
mundo, como radares de voluntades de esa comunidad que viene $e^{14} \mathrm{y}$ que comprendemos, no ya porque la vemos y tocamos, sino por todo lo que de ella reconocemos en nosotros/as mismos/as como posibilidad y potencia.

Ahora que esta imagen excesiva nos ha vuelto sensibles a los dramas de la luz mínima, podemos renunciar a los privilegios de las imágenes imperativamente visuales. Cuando uno sueña frente a una vela, solitario y ocioso, enseguida comprende que esa vida que brilla es también una vida que habla. (Bachelard 39)

\section{María Antonia Hidalgo Rubio}

Investigadora doctoranda en Ciencias Sociales, línea Género-Igualdad, UPo. Directora del Máster en Arteterapia y Aplicaciones del Arte para el Diálogo y la Integración Social de la Universidad Pablo de Olavide de Sevilla, España. Exdirectora del Área de Cultura de la Diputación de Granada. Magister en Artes Visuales y Educación. UGR.

${ }^{14}$ En Agamben, la comunidad por-venir. 
María Antonia Hidalgo Rubio

\section{ObRAS CitAdAS}

Agamben, Giorgio. La comunidad que viene. 1996. Valencia: Pre-Textos, 2016. Impreso

Albrow, Martin. The global age. Stanford: Stanford University Press, 1996. Impreso Bachelard, Gastón. La llama de una vela. 1961.Buenos Aires: El Cuenco de Plata, 2015. Impreso

Bauman, Zygmunt. La globalización. Consecuencias humanas. 2001. México: Fondo de Cultura Económica 2017. Impreso

Bauman, Zygmunt. Modernidad Líquida. México: Fondo de Cultura Económica 2004. Impreso

Benjamin, Walter. La obra de arte en la época de su reproducción mecánica. 1939. Madrid: Casimiro Libros, 2017. Impreso

Castells, Manuel. La era de la información. Economía, sociedad y cultura. La sociedad red. Madrid: Alianza Editorial, 2005. Impreso

Cavallé Cruz, Mónica. La sabiduría recobrada. Filosofía como terapia. Barcelona: Kairós, 2011. Impreso

Chul-Han, Byung. La sociedad de la transparencia. Barcelona: Herder, 2012. Impreso

Chul-Han, Byung. El aroma del tiempo. Un ensayo filosófico sobre el arte de demorarse. Barcelona: Herder, 2015. Impreso

Debord, Guy. La sociedad del espectáculo. 1996. Valencia: Pre-textos, 2015. Impreso

Gadamer, Hans-George. La actualidad de lo bello. 1977. Barcelona: Paidós, 2010. Impreso

Gallardo, Helio. Política y transformación social. Discusión Sobre Derechos Humanos. Quito: Tierra Nueva, 2000. Impreso

Garcés, Marina. Filosofía inacabada. Barcelona: Galaxia Gutenberg, , 2015. Impreso

Garcés, Marina. Fuera de clase. Textos de filosofía de guerrilla. Barcelona: Galaxia Gutenberg, 2016. Impreso 
Gubern, Román. Val del Omar, cinemista. Granada: Los Libros de la Estrella, Diputación de Granada, 2004. Impreso

Herrera Flores, Joaquín. O nome do Riso. Breve tratado sobre arte e dignidade. Trad. Nilo Kaway. Porto Alegre: Movimiento; Florianópolis: CEsusC; Florianópolis: Bernúncia, 2007. Impreso

Lacy, Suzanne. Debated Territory: Toward a Critical Language for Public Art. Seattle: Bay Press, 1995. Impreso

Musitu Ochoa, Gonzalo y Luis Amador Muñoz. Exclusión social y diversidad. México: Trillas, 2011. Impreso

Naciones Unidas. "Non self governing”. Web. <http://www.un.org/en/decolonization/nonselfgovterritories.shtml>

Santos, Boaventura de Sousa. Una epistemología del Sur. 2009. Buenos Aires: Consejo Latinoamericano de Ciencias Sociales, 2013. Impreso

Scott, James. Los dominados y el arte de la resistencia.1990. País Vasco: Ediciones Txalaparta, 2003. Impreso

Tamayo Acosta, Juan José, y Edgardo Rodríguez Gómez. Aportación de la Teología de la Liberación a los Derechos Humanos. Madrid: Dykinson, 2008. Impreso

Van Gogh, Vincent. Cartas a Theo. 1968. Barcelona: Labor, 1998. Impreso

Woolf, Virginia. Una habitación propia. 1929. Barcelona: Seix Barral, 2008. Impreso 